\title{
Em busca da saúde brasileira
}

\section{In search of Brazilian bealth}

\author{
Márcia Regina Barros da Silva \\ Pesquisadora do Centro de História e Filosofia das Ciências da Saúde (UNIFESP) \\ Rua Tiro ao Pombo, 402/94 bloco 31 \\ 02844-060, São Paulo — SP Brasil \\ mbarros.cehfi@epm.br
}

\begin{abstract}
Macondo era então uma aldeia de vinte casas de barro e taquara, construídas à margem de um rio de águas diáfanas que se precipitavam por um leito de pedras polidas, brancas e enormes como ovos pré-históricos. O mundo era tão recente que muitas coisas careciam de nome e para mencioná-las se precisava apontar com o dedo
\end{abstract}

(Gabriel Garcia Marques, Cem anos de solidão).

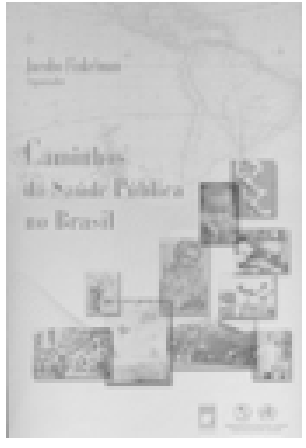

Jacobo Finkelman (org.) Caminhos da saúde pública no Brasil Rio de Janeiro, Editora Fiocruz, 2002, 326p.
B em se poderia introduzir o livro Caminhos da saúde pública no Brasil pelo título talvez mais conhecido do escritor colombiano Garcia Marques, Cem anos de solidão. Este livro dá, em alguma medida, um termo de comparação às histórias das doenças públicas que coabitam o território brasileiro junto com suas diversas populações. Seja porque se pode dizer que Garcia Marques trazia em suas raízes uma relação cotidiana com diferentes processos de saúde e doença que fica aparente no livro - seu pai era proprietário de uma farmácia homeopática -, seja porque a América Latina, região não-imaginária de que fala o livro, também estabeleceu muito das suas relações internas e de vizinhança como um espaço de experimentação sobre a doença e a saúde, por exemplo como sede de um dos primeiros organismos internacionais de cooperação a atuarem no mundo, especialmente nessa área, a Organização PanAmericana de Saúde (OPAS), criada em 1902

Para celebrar o centenário da OPAS foi preparada uma publicação com organização de Jacobo Finkelman, representante da instituição no Brasil, e coordenada por Nísia Trindade, diretora da Casa de Oswaldo Cruz; João Batista Risi Junior, coordenador do Projeto de Informação em Saúde da OPAS; Roberto Passos Nogueira, do IPEA e da Universidade de Brasília; e Otávio Azevedo Mercadante, secretário-executivo do Ministério da Saúde, além de diversos colaboradores.

O livro é dividido em três partes. A primeira intitula-se 'O Brasil e a Organização Pan-Americana da Saúde: uma história de três dimensões'; a segunda, 'As condições de saúde no Brasil'; e a terceira, 'Evolução das políticas e do sistema de saúde no Brasil'.

A unidade dos textos vai além do objeto comum de análise, a saúde pública no Brasil. Ela pode ser também verificada pela construção em

\footnotetext{
${ }^{1}$ Sobre o tema ver as duas publicações produzidas pela própria organização: Paz Soldan, C. E. La OMS y la Soberania Sanitaria de las Americas. Lima, 1949 e PAHO. Celebrating 100 years of Health. Pan American Health Organization. Washington DC. 2002
} 
conjunto de uma conclusão absolutamente necessária para o momento atual, a de que a saúde é um processo amplo, relacionado às condições socioeconômicas e culturais das pessoas que vivem em determinada localidade.

O primeiro capítulo é o que fornece as maiores possibilidades interpretativas para se pensar as constantes e as variáveis que compõem o cenário da saúde na história do Brasil. Neste capítulo torna-se possível acompanhar algumas das diferentes discussões que se travaram sobre a questão da saúde pública e que englobavam propostas de definição de uma nacionalidade brasileira. A autora parte da problematização, bastante discutida na historiografia, do Brasil como um imenso hospital, e vai até a perspectiva, inaugurada em fins dos anos 1960, da saúde como um "componente essencial do desenvolvimento" (p. 82). Nas palavras de Nísia Trindade, "... uma das constatações que se fazem imperiosas é exatamente o alargamento da agenda da saúde, em grande medida relacionado ao aumento da consciência sobre a interdependência nas sociedades humanas no final do século XX" (p. 94).

É neste capítulo também que se torna mais imediata a discussão sobre o papel da OPAS no Brasil. Inicialmente pela avaliação do organismo como responsável por auxiliar na difusão de idéias científicas relacionadas à saúde, por meio das conferências sanitárias e do boletim da instituição, no período que vai até o início dos anos 1950 e, num segundo momento, nos anos pós-guerra, pela análise da criação da Organização Mundial da Saúde (OMS) e do crescimento da ingerência do governo norte-americano em relação às políticas internas de países latino-americanos.

A escolha da autora foi por produzir um pequeno mapa de alguns dos mais conhecidos estudos sobre o tema da saúde na historiografia do Brasil. A partir daí ela pôde desenhar um quadro da saúde no país do século XIX até períodos mais recentes, analisando o crescimento da interação do Brasil nos programas desenvolvidos pela OPAS e discutindo, paralelamente, como se dava o aumento da influência dos países da América Latina na instituição. A organizadora desse capítulo é responsável ainda por um conjunto de imagens a respeito de alguns momentos significativos da saúde pública no Brasil, assim como sobre personalidades e material referente a OPAS.

No capítulo dois o panorama apresentado é o da discussão dos principais indicadores de saúde do Brasil: taxas de natalidade e fecundidade, de expectativa de vida e de mortalidade infantil, entre outros "determinantes básicos das condições de saúde", como saneamento, saúde ambiental, nutrição, doenças transmissíveis e doenças crônico-degenerativas.

A conclusão nada espantosa que se segue a essa avaliação é de que a "freqüência de qualquer doença, com raras exceções, aumenta com a redução do nível social e econômico dos grupos sociais" (p. 217).

Apesar de partir da avaliação, no tempo, das questões descritas acima, o capítulo dois não realiza exatamente uma problematização histórica, mas um balanço qualitativo e quantitativo das políticas de saúde e suas implicações e impactos para a composição dos indicadores de saúde brasileiros. Ao avaliar os padrões epidemiológicos do país, os autores procedem a um apanhado geral sobre as doenças mais prevalentes. Umas, como a febre amarela, que uma vez extintas têm marcante retorno ao quadro nosológico brasileiro, e outras, como a malária e a tuberculose, que nunca 
saíram do horizonte das nossas patologias, mas apresentaram melhoria no período tratado.

O texto não aprofunda a análise do tema, até mesmo pelo grande número de colaboradores e pela fragmentação do texto, pois não atenta para as relações mais gerais das questões de saúde com o contexto latinoamericano, por exemplo, já que falamos da OPAS, e nem mesmo discute os processos internos de descontinuidade das políticas públicas de saúde. Porém o capítulo é bastante interessante para a construção de uma visão do conjunto dos problemas de saúde existentes, como as doenças 'modernas' que se apresentam no cenário mundial hoje, a exemplo da Aids e do diabetes, e dos novos tipos de dificuldades que atingem as sociedades mais urbanizadas, como os acidentes de trânsito e a questão da violência de modo geral.

O terceiro capítulo analisa mais especificamente as principais políticas de saúde pública e os componentes da assistência à saúde adotados no país. Essa análise também é iniciada com uma pequena abordagem histórica sobre a composição da seguridade social brasileira, seus primórdios, com as famosas caixas de aposentadorias e pensão, até o Sistema Único de Saúde, o SUS.

Os conceitos mais recentes de atendimento, tais como aqueles vinculados ao Programa de Saúde da Família (PSF) e a assistência à saúde mental, está avaliada brevemente, são examinados como processos ainda em construção que, principalmente a partir dos anos 1990, tentam algo bastante difícil: tornar viável a promoção à saúde de maneira equânime e continuada. É possível perceber que a fragmentação que atinge o universo da saúde gera dificuldades de orientação e que essas dificuldades não são, certamente, inerentes ao livro, mas ao longo processo de adversidade 2 que enfrentam a medicina e as populações doentes no Brasil e na América Latina, processos que parecem ainda de difícil solução.

Numa análise geral, acredito que a leitura de Caminhos da saúde pública no Brasil auxilia grandemente na divulgação da própria história das ciências, principalmente da medicina, evidenciando, como o livro o faz, algumas das possibilidades interpretativas que a história pode fornecer para as discussões atuais e futuras sobre políticas públicas de saúde. Em segundo lugar, a leitura pode fornecer ainda, ao estudioso desses temas, suporte para acompanhar uma produção reflexiva extensa, já existente, por meio de uma ampla bibliografia, também impulsionando a vontade de aprofundar o conhecimento sobre os rumos e os destinos da saúde pública brasileira.

As últimas palavras do romance citado anteriormente dizem que tudo o que havia acontecido “... era irrepetível desde sempre e por todo o sempre, porque as estirpes condenadas a cem anos de solidão não tinham uma segunda oportunidade sobre a terra".

No nosso caso também é possível que não tenhamos uma segunda chance, tantos são os acertos e principalmente os erros perpetrados em nome da saúde

\footnotetext{
${ }^{2}$ Uma análise geral sobre as abordagens adotadas na história das ciências relacionada à América Latina pode ser vista em Marcos Cueto, 'Science under adversity: Latin American medical research and american private philanthropy, 1920-1960'. Minerva, 35, pp. 233-45, 1997.
} 
MARIA REGINA BARROS DA SILVA

pública que ainda precisam ser discutidos. Estes cem anos de OPAS e de saúde pública no Brasil nos condenam a procurar respostas para os problemas de saúde e a refletir sobre as oportunidades que precisamos inventar para tentar resolver, criativa e profundamente, as sérias contradições da saúde brasileira.

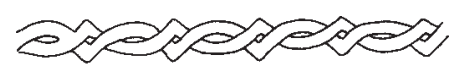

